\title{
Topical Therapy of Acute Cutaneous Leishmaniasis Using Zinc Sulphate Solution 25\% versus Podophyllin Solution 25\%
}

\author{
Khalifa E. Sharquie*, Adil A. Noaimi, Zinah A. A. Sharara, Banaz A. Saleh, \\ Wasnaa S. Al-Salam
}

Department of Dermatology, College of Medicine, University of Baghdad, Iraqi \& Arab Board for Dermatology \& Venereology, Baghdad Teaching Hospital, Medical City, College of Medicine, Baghdad, Iraq

Email: *ksharquie@ymail.com, adilnoaimi@yahoo.com, zeena.shararah@gmail.com,banazali@yahoo.com, wasnaa.alsalam@hotmail.com

How to cite this paper: Sharquie, K.E., Noaimi, A.A., Sharara, Z.A.A., Saleh, B.A. and Al-Salam, W.S. (2017) Topical Therapy of Acute Cutaneous Leishmaniasis Using Zinc Sulphate Solution 25\% versus Podophyllin Solution 25\%. Journal of Cosmetics, Dermatological Sciences and Applications, 7, 258-274.

https://doi.org/10.4236/jcdsa.2017.73024

Received: June 3, 2017

Accepted: September 26, 2017

Published: September 30, 2017

Copyright $\odot 2017$ by authors and Scientific Research Publishing Inc. This work is licensed under the Creative Commons Attribution International License (CC BY 4.0).

http://creativecommons.org/licenses/by/4.0/

c. (i) Open Access

\begin{abstract}
Background: Zinc sulphate as intralesional and oral therapy was used as a successful therapy in treatment of cutaneous leishmaniasis while $25 \%$ topical podophyllin is now commonly used in the treatment of cutaneous leishmaniasis. Objective: To treat acute cutaneous leishmaniasis using topical zinc sulphate solution $25 \%$ to be compared with topical podophyllin solution $25 \%$. Patients and Methods. This is a single, blind, interventional, comparative study done in the Department of Dermatology, Baghdad Teaching Hospital, Baghdad, Iraq during the period from January 2015 to June 2015. Forty patients with a total 88 lesions of acute cutaneous leishmaniasis were enrolled in this study; 54 (61.36\%) were dry lesions and 34 (38.6\%) were ulcerative type. The duration of lesions ranged from $2-11(7.7+2.483)$ weeks. The size of the lesions ranged from 0.3 to $8(2.13 \pm 1.53) \mathrm{cm}$. There were 21 females and 19 males, female to male ratio (1.1:1) and their ages ranged from 1 to $60(25.92 \pm$ 16.59) years. Diagnosis was confirmed by tissue smear and histopathology. Lesions were divided into two groups with matching types and sizes, and scored according to Sharquie modified Leishmania score to assess the objective response to the topical or systemic therapy and then during follow up responses were graded into mild, moderate, marked response and complete clearance. Group A treated with topical 25\% podophyllin solution once weekly for a maximum of 6 weeks, while group B was treated with topical $25 \%$ zinc sulphate solution twice daily for 6 weeks. Follow up was every 2 weeks during therapy, and once monthly for 3 months after therapy. Results. A total of 40 patients with clinical diagnosis of acute cutaneous leishmaniasis were included in this study, with a total of 88 lesions. Fifteen (37.50\%) patients had
\end{abstract}


single lesion and $25(62.50 \%)$ patients had multiple lesions. Family history of CL was positive in $42.5 \%$ of patients. At the end of six weeks after starting therapy, the total cure rate in patients treated by topical podophyllin (both marked and complete responses) was seen in 32 (82\%) lesions, while the cure rate in patients treated by topical zinc sulphate was in $36(73.4 \%)$ lesions. There was no statistical significant difference between the cure rates of both groups. No important local or systemic side effects were seen in any patients. Conclusion: Topical zinc sulphate $25 \%$ is an effective simple non-invasive non-costly safe topical therapy for cutaneous leishmaniasis and without any contraindications for its use and free of side effects and was as effective as topical podophyllin.

\section{Keywords}

Cutaneous Leishmaniasis, Topical Zinc Sulphate, Topical Podophyllin, Sharquie's Modified Leishmania Score

\section{Introduction}

Cutaneous leishmaniasis (CL) results from the parasitization of skin macrophages and generally is manifested as a papule that enlarges to a nodule that often ulcerates. Diverse leishmania species cause cutaneous leishmaniasis. In Iraq cutaneous leishmaniasis is mainly caused by L. major (60\%) and L. tropica (40\%) [1].

Many important strides have been made in treatment and control of cutaneous leishmaniasis. However, there are still approximately 1.5 million new cases of CL each year worldwide, with the bulk reported from Afghanistan, Iran, Iraq, Algeria, Saudi Arabia, Pakistan [2]. According to the World Health Organization (WHO); leishmaniasis is endemic in 88 countries, with a total of 350 million people at risk, it is believed that worldwide 12 million people are currently infected by leishmaniasis [3]. CL was endemic disease in Iraq since ancient times and from time to time outbreak andlor epidemic occurs. On 2014 an outbreak occurred in Iraq when hundreds of patients had been seen since October 2014 till April 2015 due to floods that occurred after heavy rains also by the role of terrorist who opened the gates of dams (Fallujah dam) on Euphrates river that resulted in floods in many towns and villages leading to spread of rodents the reservoir of leishmaniasis.

Most CL lesions are self limiting but spontaneous cure may take several months or even years. In spite of this, treatment is justified in a variety of cases, namely early lesions, multiple lesions, lesions involving cosmetically sensitive sites, and patients with significant immunosuppression. In addition psychological impact of the disease cannot be ignored. The aim of therapy is namely clinical healing and disappearance of parasites. The disease still presents a therapeutic challenge in several parts of the world. Unfortunately to date there is no safe, 
simple, cheap and effective ambulatory treatment for CL. Pentavalent antimony compounds; still remain the mainstay of treatment in the majority of cases. However, these have the disadvantage of both toxicity and clinical resistance in certain regions. Other treatment options given systemically have found favor in some studies [4]; such as imidazole compound, allopurinol, rifampicin, dapsone, zinc sulfate [5] and chloroquine [6]. Local infiltration of drug have the advantage of direct effect on parasite due to chemical and osmotic mechanisms such as intralesional sodium stibogluconate antimony [7] and intralesional hypertonic sodium chloride solution (7\%) [8], while intralesional zinc sulphate $2 \%$ didn't act as osmotic effect, when zinc sulphate was added to axenic amastigotes of both species of Leishmania it caused immediate death. There was no change in the shape of either forms with zinc sulphate, in contrast to $7 \%$ hypertonic saline that caused parasite shrinkage beside sudden paralysis [9]. Physical methods have also been tried with success such as microwave thermotherapy [10], $\mathrm{CO}_{2}$ laser [11], Cryotherapy [12]. For simple cutaneous lesions which are few in number and where there is no risk of disfigurement or joint mobility restriction, topical application or local treatment would be a valuable option and often justified and many have been used like; azoles compound like; topical ketoconazole [13], clorimazole cream and miconazole cream [14]. Other compounds like; topical paramomycine [15] and recently topical podophyllin with $85 \%$ cure rate [16]. Topical therapy is an attractive choice as it is less toxic than systemic ones, and non painful as compared to intralesional therapies. Zinc sulphate had been used successfully in treatment of cutaneous leishmaniasis both systemically and intralesionally in treatment of CL with an encouraging cure rates [5] [8]. Accordingly the present work was arranged to evaluate topical zinc sulphate $25 \%$ as an alternative therapy for $\mathrm{CL}$ and to be compared with effective topical therapy like $25 \%$ podphyllin.

\section{Patients and Methods}

This is a single blinded, interventional, comparative study done in the Department of Dermatology, Baghdad Teaching Hospital, Baghdad, Iraq, from January 2014 to June 2014.

A full history was taken from each patient regarding the followings: age, address, duration of the lesions and their number, recurrence of the lesion, history of previous therapy, also family history, past medical history, obstetric history regarding the females in reproductive period and past drug history.

A total of 48 patients with typical acute CL, had been enrolled in this study. Eight patients with a total of 10 lesions were defaulted for unknown reasons. So the number of patients that completed the study were 40 patients with a total of 88 lesions; 54 (61.36\%) were dry type and 34 (38.6\%) ulcerative type. The duration of lesions ranged from 2 - 11 weeks with mean \pm SD of $(7.7 \pm 2.483)$ weeks. The size of the lesions ranged from 0.3 to $8 \mathrm{~cm}$ with mean $\pm \mathrm{SD}$ of $(2.13 \pm 1.53)$ $\mathrm{cm}$. 
There were twenty one females and 19 males, female to male ratio $(1.1: 1)$ and their ages ranged from 1 to 60 years with mean \pm SD of $(25.92 \pm 16.59)$ years.

Skin examination was performed including the site, size and type of the lesions; and regional lymphadenopathy.

Patients with the following criteria were excluded from this study:

Pregnancy, chronic diseases, immunosuppressed like diabetes mellitus, peripheral neuropathy, poor peripheral circulation, and prolonged corticosteroid therapy, lesions with surface area more than $10 \mathrm{~cm}^{2}$ or lesions close to eyes, patients who received anti-leishmanial treatment either local or systemic, if the lesions of more than 12 weeks duration were excluded because the possibility of self healing during follow-up period. Patients with re-infestation were also excluded.

After full interrogation and explanation to each patient about the nature of disease including its course, complications and prognosis, treatment modalities and their complications, a formal consent was taken from each patient.

Serial photos were taken in the same place in each visit, with fixed illumination and distance, using Samsung ${ }^{\circledR}$ Galaxy S3 mobile camera with 8 Megapixels. Also, the ethical approval was granted by the Scientific Committee of the Scientific Council of Dermatology-Iraqi Board for Medical Specializations. In all patients, the diagnosis was established by history and clinical examination, and confirmed by dental broach smear and $3 \mathrm{~mm}$ punch biopsy for histopathological examination.

Smear was done by cleaning the lesion with $70 \%$ alcohol then using a dental broach. A sample was taken from more than one area of the lesion, smeared onto a clean glass slide, and stained with Leishman stain. Then a microscopical examination of the smear was done to demonstrate the amastigotes inside or outside the macrophages.

According to the therapy, the lesions had been divided into two groups with matching of types and sizes of lesions. Statistically, there was no significant difference between the two treated groups, regarding the number of the ulcerated and the non ulcerated lesions in each group, where, $\chi^{2}=3.761$ and $P$ value $=0.52$ (Table 3).

\section{Group A: Treated by $25 \%$ topical podophyllin in tincture benzoin:}

Twenty patients with a total of 39 lesions; 20 (51.28\%) lesions were dry and 19 (48.72\%) lesions were ulcerative, all treated with $25 \%$ topical podophyllin in tincture benzoin that was prepared by dissolving $25 \mathrm{~g}$ of podophyllin resin powder, purchased from Merck Company, Germany, in $100 \mathrm{ml}$ of tincture benzoine and was kept sealed in dark place within dark glass container in room temperature. The solution was applied with cotton-tipped applicator. For the non ulcerated type, the lesion was covered with thin layer of solution, while for ulcerated type; the solution was applied to the margin of the ulcer. The amount of solution that was used in each session did not exceed 0.5 milliliter and the surface area treated did not exceed 10 square centimeters, in order to minimize 
the local and the systemic side effects of the drug. The solution was allowed to dry in approximately 2 minutes and patients were instructed to wash off it after 6 hours. The solution was applied once weekly for maximum 6 weeks.

\section{Group B: Treated by topical $25 \%$ zinc sulphate:}

Twenty patients with a total 49 lesions; 35 (71.43\%) lesions were dry and 14 (28.57\%) lesions were ulcerative; all were treated with twice daily application of topical $25 \%$ zinc sulphate that was prepared by dissolving $25 \mathrm{~g}$ of zinc sulphate powder (heptahydrate purified) $\mathrm{ZnSO}_{4} \cdot 7 \mathrm{H}_{2} \mathrm{O}$, M.W. 287.54, purchased from THOMAS BAKER Company, India, in $100 \mathrm{ml}$ of distilled water and kept in dark glass container in room temperature. The solution was applied with a cotton tipped applicator and not to wash off, this was done twice daily for a maximum 6 weeks.

\subsection{Assessment to Response of Therapy}

Each lesion was assessed in the first visit through detecting the color of erythema and its diameter, measuring the size of each lesion was carried out by palpation and marking the induration and measuring its diameter with a caliber in centimeters unit. For rounded regular lesions one diameter was taken, while in irregular lesions the two maximum diameters (length and width) were taken to calculate the mean, in ulcerative lesion the diameter of ulcer was measured also.

Sharquie has modified his previous score to become more sensitive and specific; so scoring was done using "Sharquie modified leishmania score to assess the objective response to topical or systemic therapy" [17] (Table 1).

\subsection{Follow-Up}

Patients in both groups were followed up every 2 weeks during the treatment period that continued for six weeks, and then monthly for three months after

Table 1. Sharquie's modified Leishmania score to assess the objective response to the topical or systemic therapy.

\begin{tabular}{|c|c|c|c|c|}
\hline Score & $\begin{array}{l}\text { Change in the } \\
\text { color of lesion }\end{array}$ & $\begin{array}{c}\text { Reduction rate in } \\
\text { the color } \\
\text { diameter of } \\
\text { lesion }\end{array}$ & $\begin{array}{l}\text { Reduction rate in } \\
\text { the induration of } \\
\text { lesion }\end{array}$ & $\begin{array}{c}\text { Reduction rate of } \\
\text { ulcer/crust }\end{array}$ \\
\hline 4 & Bright red & - & - & - \\
\hline 3 & Red & $0 \%-25 \%$ & $0 \%-25 \%$ & $0 \%-25 \%$ \\
\hline 2 & Dusky red & $>25 \%-50 \%$ & $>25 \%-50 \%$ & $>25 \%-50 \%$ \\
\hline 1 & Dark brown & $>50 \%-75 \%$ & $>50 \%-75 \%$ & $>50 \%-75 \%$ \\
\hline 0 & Light brown & $>75 \% /$ clearance & $>75 \% /$ clearance & $>75 \% /$ clearance \\
\hline
\end{tabular}

Score 16 - 12: mild response; Score 12 - 8: moderate response; Score 8 - 4: marked response; Score 4 - 0 : complete clearance. Both marked and complete responses are considered as a cure. For dry lesions; where the fourth parameter (reduction of the ulcer diameter) is not applicable; so grading was done as follow: Score 12 - 9: mild response; Score 9 - 6: moderate response; Score 6 - 3: marked response; Score 3 - 0: Complete response. 
therapy. In each visit the lesions were re-scored and response was graded accordingly, and to detect any local and systemic side effects.

\section{Statistical Analysis}

Statistical analysis was done using SPSS 20; chi square were used to compare between grades of responses in each group, paired $\mathrm{T}$ test was used to compare between means of score in each visit for particular group, $\mathrm{P}$ value less than 0.05 considered significant.

\section{Results}

A total of 40 patients with acute CL, proved clinically and confirmed parasitologically were included in this study, with a total of 88 lesions; 54 (61.36\%) of which were dry and 34 (38.6\%) lesions were ulcerative type. Fifteen (37.50\%) patients had single lesion and $25(62.50 \%)$ patients had multiple lesions. Family history of CL was positive in $42.5 \%$ of patients.

The most common sites of body that frequently affected were the upper extremities with 51 lesion (57.95\%), then the lower extremities with 26 (29.54\%), while in the trunk there were only 4 lesions (4.54\%) and neck with 5 lesions (5.68\%) lastly the face with 2 lesions (2.27\%).

1) The therapeutic response from the first visit until 6 weeks after treatment in each group were as follow: (Table 2).

Group A: a total of twenty patients with 39 lesions, 20 (51.28\%) lesions were dry type and 19 (48.72\%) lesions were ulcerative.

The baseline first visit the mean score of response \pm SD was $(13.74 \pm 2.087)$.

Two weeks after starting therapy the mean score of response \pm SD was $(10.56 \pm$ 2.17 ), this was statistically significant when compared to the first visit ( $\mathrm{p}$ value $<$ $0.0001)$.

Four weeks after starting therapy; mean score of response + SD was (7.36 \pm 2.518 ) by comparing the means with the first visit; it was statistically significant, $\mathrm{p}$ value $<0.0001$.

Six weeks after starting therapy; mean score of response \pm SD was $(4.41 \pm$ 2.314 ) which was statistically significant when compared to the first visit, ( $\mathrm{p}$ value $<0.0001$ ).

Table 2. The mean and SD of total score of response within group A and group B for each visit.

\begin{tabular}{|c|c|c|c|c|c|c|}
\hline \multicolumn{2}{|c|}{ Group } & First visit & After 2 weeks & After 4 weeks & After 6 weeks & $\begin{array}{c}\text { ANOVA } \\
\text { F/p-value }\end{array}$ \\
\hline \multirow{2}{*}{ Group A } & Mean \pm & $13.74 \pm 2.88$ & $10.56 \pm 2.518$ & $7.37 \pm 2.518$ & $4.47 \pm 2.72$ & $\mathrm{~F}=88.9$ \\
\hline & $\mathrm{P}^{*}$ & - & $<0.0001$ & $<0.0001$ & $<0.0001$ & \\
\hline \multirow{2}{*}{ Group B } & Mean \pm & $12.84 \pm 2.21$ & $10.2 \pm 1.75$ & $6.84 \pm 2.35$ & $4.47 \pm 2.72$ & $\mathrm{~F}=128.04$ \\
\hline & $\mathrm{P}^{*}$ & - & $<0.0001$ & $<0.0001$ & $<0.0001$ & p 0.0000 \\
\hline
\end{tabular}

$\mathrm{P}=\mathrm{P}$ value. ${ }^{\star}$ Paired $\mathrm{t}$ test was used to compare base line visit with other visits. 
Group B: A total twenty patients with 49 lesions; 35 (71.43\%) lesions were dry and $14(28.57 \%)$ lesions were ulcerative. The response was as follow:

The baseline first visit the mean score of response \pm SD was $(12.84 \pm 2.12)$.

Two weeks after starting therapy; the mean score of response \pm SD was $(10.2 \pm$ 1.75 ); this was statistically significant when compared to the first visit ( $\mathrm{p}$ value $<$ $0.0001)$.

Four weeks after starting therapy; mean score of response \pm SD was $(6.84 \pm$ 2.35 ) by comparing the means with the first visit; it was statistically significant, $p$ value $<0.0001$.

Six weeks after starting therapy; mean score of response + SD was $(4.47 \pm$ 2.72) which was statistically significant when compared to the first visit, ( $p$ value $<$ 0.0001) (Table 2).

Using ANOVA test to compare between the means of scores of both groups the affectivity $(F=128)$ in group $B$, and $(F=88)$ in group A. So treatment in group B is more effective (Table 2, Figure 1).

2) The percentage of grades of responses in each visit during therapy were as follow:

\section{Group A:}

Two weeks after starting the therapy:

- Mild response in 25 (64.10\%) lesions.

- Moderate response in 14 (51.90\%) lesions.

- No lesion showed marked or complete response.

Four weeks after starting the therapy:

- Mild response in 5 (12.80\%) lesions.

- Moderate response in 19 (48.70\%) lesions.

- Marked response 14 (35.90\%) lesions.

- Complete response in 1 (2\%) lesion.

At the end of six weeks after starting the therapy (Table 3):

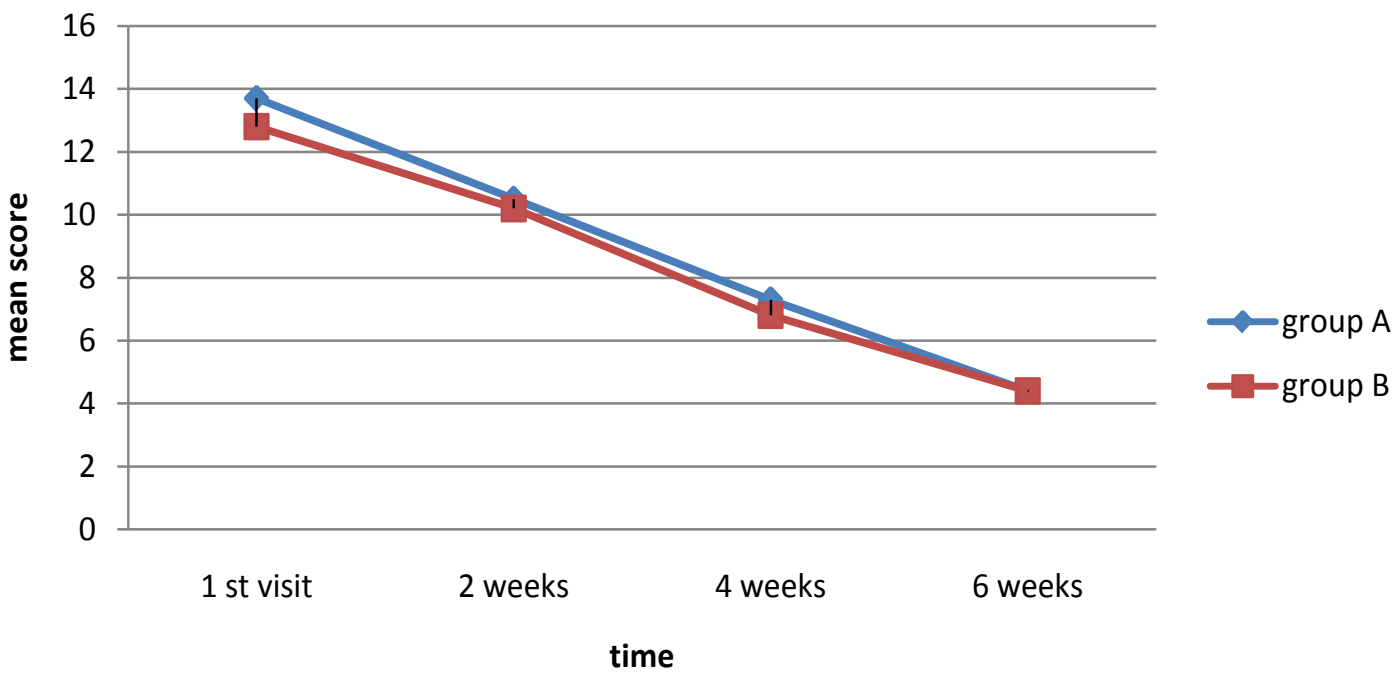

Figure 1. The decline in the means of scores during therapy. 
Table 3. The percentages of grades of responses in the treated lesions in each group 6 weeks after starting the therapy.

\begin{tabular}{ccccc}
\hline \multirow{2}{*}{ Grade of response } & \multicolumn{2}{c}{ Group A } & \multicolumn{2}{c}{ Group B } \\
\cline { 2 - 5 } & No. of lesions & $\%$ & No. of lesions & $\%$ \\
\hline Mild & 0 & $(0 \%)$ & 4 & $(8.2 \%)$ \\
Moderate & 7 & $(18 \%)$ & 9 & $(18.5 \%)$ \\
Marked & 16 & $(41 \%)$ & 25 & $(51 \%)$ \\
Complete clearance & 16 & $(41 \%)$ & 11 & $(22.4 \%)$ \\
Clinical cure & 32 & $(\mathbf{8 2 \% )}$ & 36 & $(73.4 \%)$ \\
Total & 39 & $(100 \%)$ & 49 & $(100 \%)$ \\
\hline
\end{tabular}

$\chi^{2}=6.094$. P value $=0.107$

- No lesion with mild response was detected.

- Moderate response in were 7 (17.9\%) lesions.

- Marked response in $16(41.0 \%)$ lesions.

- Complete response in $16(41.0 \%)$ lesions.

So the total cure rate (both marked and complete responses) was seen in 32 (82\%) lesions.

In all clinical cured lesions, there were no or minimum scarring at the site of lesions, but post-inflammatory hyper pigmentation was noted in all treated lesions that disappear over time. No recurrence of lesions was noticed in any patient. There were no serious local or systemic side effects (Figure 2 and Figure 3).

\section{Group B}

Two weeks after starting the therapy:

- Mild response; in 36 (73.47\%) lesions

- Moderate response; in 13 (26.53\%) lesions

- No lesion with marked or complete response.

Four weeks after starting the therapy:

- Mild response; in $9(18.40 \%)$ lesions

- Moderate response; in 23(46.90\%) lesions.

- Marked response; in $16(32.70 \%)$ lesions.

- Complete response; in 1 (2\%) lesions.

At the end of 6 weeks after starting treatment (Table 3):

- Mild response was detected in $4(8.20 \%)$ lesions.

- Moderate response in $9(18.40 \%)$ lesions.

- Marked response in $25(51.0 \%)$ lesions.

- Complete response in 11 (22.4\%) lesions.

So the cure rate in this group (both marked and complete response) was achieved in $36(73.4 \%)$ lesions.

After clinical resolution, post-inflammatory hyperpigmentation that disappear over time and minimal scarring were noticed in all lesions but no recurrence of lesion in any patients (Figure 4 and Figure 5).

There were no significant side effects in this group apart from mild burning 


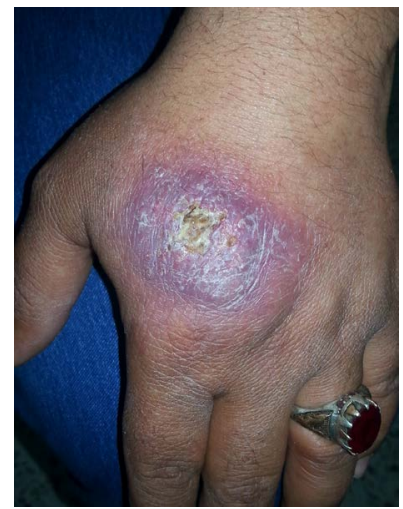

(a)

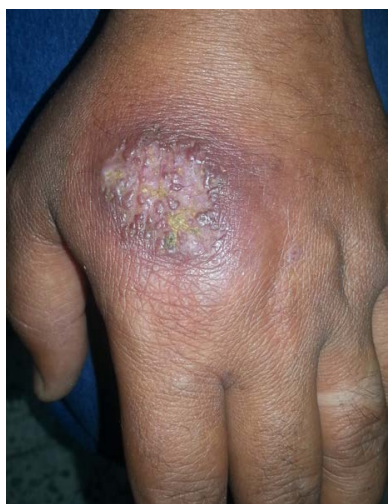

(b)

Figure 2. Twenty five years old male treated with topical podophyllin sol (25\%) (a) Before treatment. (b) 6 weeks after starting therapy.

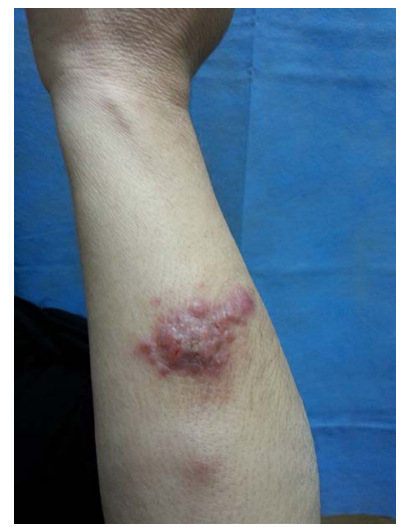

(a)

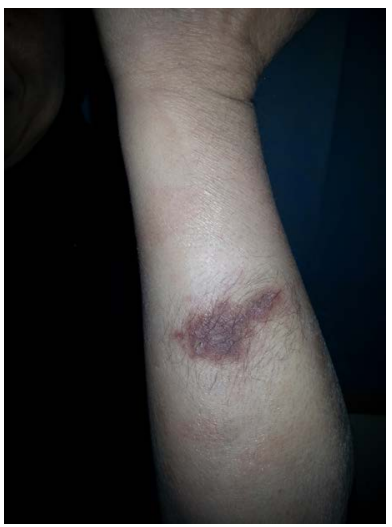

(b)

Figure 3. Forty two years old female treated with topical podophyllin sol (25\%). (a) Before treatment. (b) 4 weeks after starting therapy.

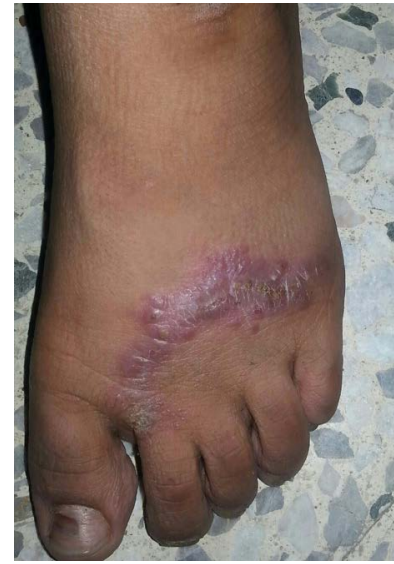

(a)

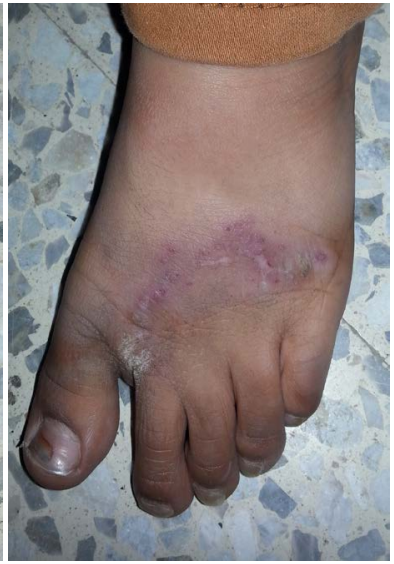

(b)

Figure 4. Twelve years old female treated with topical zinc sulphate sol (25\%). (a) Before treatment. (b) 6 weeks after starting therapy. 


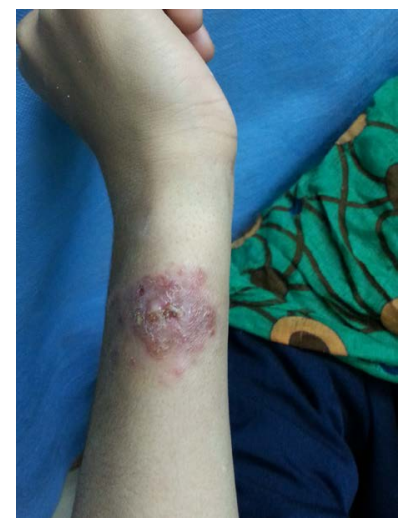

(a)

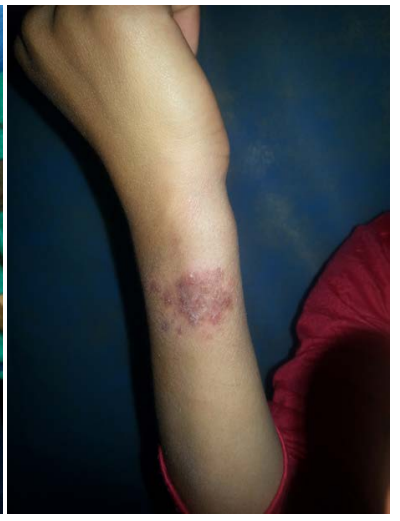

(b)

Figure 5. Ten years old child treated with topical zinc sulphate sol (25\%). (a) Before treatment. (b) 6 weeks after starting therapy.

sensation that occurred in one patient with ulcerative lesions.

3) Comparison between groups:

By comparing the percentages of grade of responses between the two groups in each visit:

- Two weeks after starting therapy $\chi^{2}=0.896, \mathrm{P}$ value $=0.344$, no statistical significant difference.

- Four weeks after therapy $\chi^{2}=0.528$ and $\mathrm{P}$ value $=0.913$, no statistical significant difference.

- Six weeks after starting therapy there were no statistical significant difference between the cure rates of both groups where $\chi^{2}=6.094$ and $\mathrm{P}$ value $=0.107$ (Table 3). In regards to lesions with complete clearance there were $16(41 \%)$ lesions showed this response in group A, while 11 (22.4\%) lesions in group B showed complete clearance which was not statistically significant difference, $(\mathrm{P}$ value $=0.06)$.

4) Comparison between dry and ulcerative lesions responses:

This study revealed that there was no statistical difference between the ulcerative lesions and dry lesions responses to each therapy; where, in group A; 16 (80\%) out of 20 dry lesions had clinical cure 6 weeks after starting the therapy; and $16(84 . \%)$ out of 19 ulcerative lesions had a clinical cure 6 weeks after starting the therapy, $\mathrm{x}^{2}=0.117$, $\mathrm{p}$ value $=0.943$.Also in group B; $24(68.6 \%)$ out of 35 dry lesions showed clinical cure, and 12 (85.7\%) out of 14 ulcerative lesions showed clinical cure at the end of six weeks therapy, $\mathrm{x}^{2}=6.739, p$ value $=0.081$; statistically not significant.

\section{Discussion}

In Iraq CL is caused by two species as proved by PCR; (40\%) L. tropica and (60\%) L. major [1]. Although this disease is endemic but now the country is showing an epidemic state. CL is a self limited disease but may continue for several months and even years [5] [7], causing great psychological trauma to the 
patients, in addition it can cause severe disfiguring with bad cosmetic appearance especially when occurs in the face, hence it's therapy is mandatory. So the aim of the treatment is to shorten the duration of the disease and to prevent scarring. On review of literature; many topical and systemic therapies were reported to be effective in clearance of cutaneous leishmania lesions [4].

Topical therapy is an attractive choice and is indicated when there is few lesions and to increase the concentration of the drug at the lesional site, then to increase its effectiveness. Also to reduce the cost of therapy and to avoid the systemic side effects of the systemic drug [18].

Many therapeutic agents that are given intralesionally had been tested previously with high success rates, like; sodium stibogluconate with (94\%) cure rate [7], hypertonic sodium (7\%) with (96\%) cure rate [19], zinc sulphate solution (2\%) with $(94.8 \%)$ cure rate [20], metronidazole with (85\%) cure rate [21], Chloroquine with (100\%) cure rate [6].

Most recently microwave thermotherapy was used with $(85.33 \%)$ cure rate [10], topical photodynamic therapy with $(93.5 \%)$ cure rate [22] and topical podophyllin with (85\%) cure rate [16], topical TCA with $65 \%$ cure rate [23].

While systemic treatment for $\mathrm{CL}$ is often advised when there are numerous and/or large lesions that can't be locally infiltrated. The current recommended systemic treatment which had been used since the 1950s is parentally administered pentavalent antimonial compounds. Although it is effective but they are expensive and may cause serious side effects [24]. Other systemic drugs that were used in treatment of CL like oral zinc sulfate, [4] [5] amphotericin B [9], rifampicin [25], antifungal agents [26]-[31], levamisole [32], dapsone [33] [34].

So the aim of present work is to use topical zinc sulphate rather than intralesional, as a simple non invasive mode of therapy for the patients, and to be compared with well-established topical therapy like $25 \%$ topical podophyllin sol [16]. Using Sharquie modified leishmania score, in the present study, to assess response to treatment, topical $25 \%$ podophyllin solution gave ( $82 \%$ ) cure rate, while the cure rate using topical $25 \%$ zinc sulphate solution was $(73.4 \%)$ and there was no statistical difference between the two therapies.

Zinc is an essential element that its concentration in skin could be increased eightfold by topical application of zinc sulphate, a concentration of 3\% was optimal [35]. Topical zinc sulphate had been used successfully in the treatment of a wide variety of skin disorders such as: plane warts [36], recurrent herpes simplex [37], superficial fungal infection [38], melasma [39], and others. Intralesional zinc sulphate had also been used effectively for basal cell carcinoma [40] and in treatment of CL with (97.8\%) cure rate [8]. Zinc acts as caustic agent that cause a sudden paralysis of parasite in vitro. As the addition of $2 \%$ zinc sulphate solution to promastigotes of either L. major or L. tropica caused immediate paralysis and death of promastigotes, moreover when zinc sulphate was added to axenic amastigotes of both species of leishmania it caused immediate death. However there was no change in the shape of either forms of parasite with the addition of zinc sulphate, in contrast, the addition of $7 \%$ hypertonic saline to this parasite caused 
its shrinkage and sudden paralysis [5]. On the other hand the live parasite growth were affected and dropped in culture containing zinc sulphate compound as compared to the parasite population in control culture [41]. Accordingly zinc sulphate which is a cytotoxic agent [42] probably interfere with enzymes of parasites rather than changing the osmotic pressure of leishmania parasite. At this stage, the exact mechanism of the anti-leishmanial effect of zinc is not well established but it can be only speculated. It is well known that zinc plays an important role in specific metalloenzyme systems concerned with nucleic acid and protein synthesis [38], furthermore zinc has been reported to inhibit DNA polymerase of herpes simplex virus [37]. Therefore, we might suggest that site of action of zinc is on enzymes that are concerned with nucleic acid metabolism. However further investigation is needed to confirm the exact mechanism of action of zinc against leishmania.

Podophyllin, is an alcoholic plant extract obtained from dried rhizomes of common plants emodi or podophyllum peltatum [24].

It is a cytotoxic drug, which had been used since the 1940s, as a topical treatment of various skin lesions especially warts [43] [44]. Also it is used in treatment of oral hairy leukoplakia [44], molluscum contagiosum [31], keratoacanthoma [45], seborrheic keratosis, actinic keratosis [46].

The mechanism of action of podophyllin is well known and as follow;

1) Podophyllin is proved to reversibly bind to tubulin which is the protein subunits of the spindle microtubules and then prevent polymerazation of the tubulin into microtubules [31] [47] [48]. The microtubules which located beneath the plasma membrane of leishmania parasite and serve as a cytoskeleton [49].

2) It blocks oxidation enzymes in tricarboxylic acid cycle. This tricarboxylic acid cycle is one of cycles that involve in the nutrition of leishmania parasite [47] [48].

3) Also, it can inhibit axonal transport, protein, and RNA and DNA synthesis and inhibit of mitochondrium activity [47] [48].

All these mechanisms could lead to death of the parasite, followed by cure of the lesion.

Topical zinc sulphate is more effective when it is compared with other topical treatments like clotrimazole cream which gave cure rate reaching to $(15.7 \%)$ while topical $2 \%$ ketoconazole cream was not found to be more effective than placebo [35].

Furthermore the cure rate of topical podophyllin and topical zinc in the present work was higher than topical trichloracitic acid (TCA), which gave (65\%) success rate [23], and higher than 5\% topical imiquimod plus intralesional meglumine antimony which achieved (40\%) cure rate [4]. The above combination beside being expensive they were irritant on application as compared to topical zinc sulphate and topical podophyllin when both were well tolerated and non costly.

Moreover it was noticed that the cure rates of topical podophyllin and topical 
zinc sulphate individually were higher or approximate to topical paramomycine responsiveness that had been reported from $(16.7 \%$ to $78 \%)$ in the studies of a 2 -weeks regimen and up to (80\%) in 4-weeks regimen study. Topical paramomycine had burning side effect and severe inflammatory reaction; in addition this drug is costly and unavailable [4] [15].

Cryotherapy had been used in the treatment of CL with $67.8 \%$ cure rate and with many side effects especially ugly scarring and permanent hypopigmentation; in addition to that, it was a painful method [4] [12].

In regards to intralesional sodium stiboglugonate which gave a high cure rate reaching to (94\%) with one or 2 injections, but this drug is costly, not available, difficult in storage [7]. Also in comparison with $2 \%$ zinc sulphate solution that was given intralesionally at 10 days intervals, the cure rate reached to (97.8\%) usually with one or 2 injections [8], both above two drugs were painful when given intralesionally especially in children and need to be mixed up with xylocain and their mechanism of action, as antileishmanial drugs, was presumably as a result of their metallic contents which probably induce tissue damage and, subsequently, severe inflammatory changes had occurred [8].

The cure rates in the present work are less than intralesional hypertonic sodium chloride 7\% which is given every $7-10$ days interval for 6 weeks, as it reached (96\%), but topical zinc is non painful topical method, that doesn't need recurrent hospital visits [19].

In the present work, all the clinical cured lesions healed with minimal scarring and this result was similar to that reported in other modalities of treatment e.g. intralesional pentavalent antimonial compounds [7] and intralesional $2 \%$ zinc sulphate [8], intralesional 7\% hypertonic sodium chloride [8], topical paromomycin [4]. Also there was no serious local or systemic side effects, apart from mild burning sensation that occurred in one patient in the zinc group. Post inflammatory hyperpgimentation was noticed in all patients in each group and disappear over time. These side effects were similar and sometimes less than other modalities [18] [20].

\section{Conclusion}

In conclusion, topical zinc sulphate sol. $25 \%$ gave $74.3 \%$ cure rate versus $82 \%$ cure rate in $25 \%$ podophyllin sol. Hence topical zinc sulphate therapy is noninvasive simple non-costly therapy that could be used alone or in combination with other topical or systemic therapy in the treatment of acute cutaneous leishmaniasis.

\section{Disclosure}

This study was an independent study and not funded by any drug companies.

\section{References}

[1] Sharquie, K.E., Al-Najar, S.A., Noaimi, A.A. and Al-Hesany, A.R. (2014) Cutaneous 
Leishmaniasis: Comparative Techniques for Diagnosis. IOSR Journal of Dental and Medical Sciences (IOSR-JDMS), 13, 33-37. http://www.iosrjournals.org/

[2] Desjeux, P. (2004) Leishmaniasis: Current Situation and Perspectives. Comparative Immunology, Microbiology \& Infectious Diseases, 27, 305-318.

https://doi.org/10.1016/j.cimid.2004.03.004

[3] WHO. http://www.who.int/topics/epidemiology/en/

[4] González, U., Pinart, R.L. and Alvar, J. (2008) Interventions for Old World Cutaneous Leishmaniasis. Cochrane Database of Systematic Reviews, No. 4. Art. No.: CD005067.

[5] Sharquie, K.E., Najm, R.A., Farjou, I.B. and Al-Timimi, D.J. (2001) Oral Zinc Sulfate in the Treatment of Acute Cutaneous Leishmaniasis. Clinical and Experimental Dermatology, 26, 21-26. https://doi.org/10.1046/j.1365-2230.2001.00752.x

[6] Khan, I.A., Yasmin, R. and Sidiqui, I. (2007) Chloroquine in Cutaneous Leishmaniasis. Journal of Pakistan Association of Dermatologist, 17, 95-100.

[7] Sharquie, K.E. and Al-Talib, K. (1988) Intralesional Therapy of Cutaneous Leishmaniasis with Sodium Stibogluconate Antimony. British Journal of Dermatology, 119, 53-57. https://doi.org/10.1111/j.1365-2133.1988.tb07100.x

[8] Sharquie, K.E., Najem, R.A. and Farjou, I.B. (1997) A Comparative Control Trail of Intralesional Administrated Zinc Sulfate, Hypertonic Saline Chloride and Pentovalent Antimony Compound against Acute Cutaneous Leishmaniasis. Clinical and Experimental Dermatology, 22, 169-173. https://doi.org/10.1111/j.1365-2230.1997.tb01054.x

[9] Sharquie, K.E., Najem, R.A. and Farjou, I.B. (1998) Zinc Sulfate in Treatment of Cutaneous Leishmaniasis an in Vitro and Animal Study. Memórias do Instituto Oswaldo Cruz, 93, 831-837. https://doi.org/10.1590/S0074-02761998000600025

[10] Sharquie, K.E., AL-Mashhadani, S.A., Noaimi, A.A. and Al-Zoubaidi, W.B. (2015) Microwave Thermotherapy; New Treatment for Cutaneous Leishmaniasis. Our Dermatology Online, 6, 125-129.

[11] Shamsi, M.S., Zandi, S., Aghaie, H. and Heshmatkhah, A. (2011) Efficacy of $\mathrm{CO}_{2}$ Laser for Treatment of Anthroponotic Cutaneous Leishmaniasis, Compared with Combination of Cryotherapy and Intralesional Meglumine Antimoniate. Journal of the European Academy of Dermatology and Venereology, 25, 587-591. https://doi.org/10.1111/j.1468-3083.2010.03781.x

[12] Salmanpour, R., Razmavar, M.R. and Abtahi, N. (2006) Comparison of Intralesional Meglumine Antimoniate, Cryotherapy and Their Combination in the Treatment of Cutaneous Leishmaniasis. International Journal of Dermatology, 45, 1115-1116. https://doi.org/10.1111/j.1365-4632.2006.02822.x

[13] Mameni, A.Z., Aminijavaheri, M. and Omidghaemi, M. (2003) Treatment of Cutaneous Leishmaniasis with Ketoconazole Cream. Journal of Dermatological Treatment, 14, 26-29. https://doi.org/10.1080/09546630305552

[14] Larbi, E.B., Al Khawajah, A., Al-Gindan, Y., Jain, S., Abahusain, A. and Al-Zayer, A. (1995) A Randomized Double-Blind Clinical Trial of Topical Clorimazole vesus Miconazole for Treatment of Cutaneous Leishmaniasis in the Eastern Provice of Saudi Arabia. The American Journal of Tropical Medicine and Hygiene, 52, 166-168. https://doi.org/10.4269/ajtmh.1995.52.166

[15] Faghihi, G. and Tavakoli-kia, R. (2003) Treatment of Cutaneous Leishmaniasis with Either Topical Paramycin or Intralesional Meglumine Antimoniate. Clinical and Experimental Dermatology, 28, 13-16. https://doi.org/10.1046/j.1365-2230.2003.01169.x 
[16] Sharquie, K.E., Noaimi, A.A. and Al-Ghazzi, A.G. (2015) Treatment of Cutaneous Leishmaniasis by Topical 25\% Podophyllin Solution (Single, Blinded, Therapeutic, Controlled Study). Journal of Dermatology \& Dermatologic Surgery, 108-113.

[17] Sharquie, K., Noaimi, A. and Al-Salam, W. (2016) Treatment of Acute Cutaneous Leishmaniasis by Oral Zinc Sulfate and Oral Ketocanazole Singly and in Combination. Journal of Cosmetics, Dermatological Sciences and Applications, 6, 105-1154. https://doi.org/10.4236/jcdsa.2016.63014

[18] Pujol, A. and Riera, C. (2014) Review and New Therapeutic Alternatives for the Treatment of Cutaneous Leishmaniasis. Research Signpost, 37, 181-201.

[19] Sharquie, K.E., Hussian, A.K. and Turki, K.M. (1994) Intralesional Therapy of Cutaneous Leishmaniasis with Hypertonic Sodium Chloride Solution. Pan-Arab Ass Dermatologists, 5, 85-91.

[20] Sharquie, K.E. (1995) A New Intra-Lesional Therapy of Cutaneous Leishmaniasis with Hypertonic Sodium Chloride Solution. The Journal of Dermatology, 22, 732-737. https://doi.org/10.1111/j.1346-8138.1995.tb03911.x

[21] Sharquie, K.E., Al-Waize, M. and Al-Asser, M. (2004) Therapy of Cutaneous Leishmaniasis with Intralesional Metronidazole. Saudi Medical Journal, 10, 1512-1513.

[22] Asilian, A. and Davami, M. (2006) Comparison between the Efficacy of Photodynamic Therapy and Topical Paromomycin in the Treatment of Old World Cutaneous Leishmaniasis: A Placebo-Controlled, Randomized Clinical Trial. Clinics in Dermatology, 31, 634-637. https://doi.org/10.1111/j.1365-2230.2006.02182.x

[23] Nilforoushzadeh, M.A., Jaffary, F. and Reiszadeh, M.R. (2006) Comparative Effect of Topical Trichloroacetic Acid and Intralesional Meglumine Antimoniate in the Treatment of Acute Cutaneous Leishmaniasis. International Journal of Pharmacology, 2, 633-636. https://doi.org/10.3923/ijp.2006.633.636

[24] Martin, E.C., Christy, L., Cowan, M.C., Marshal, S.W., Dawson, A.H., Seifert, S.A., Schon, W.S., Yip, L., Keyes, D.C., Hurlbut, K.M. and Erdman Arm Dart, R.C. (2004) Medical Toxicology. 3rd Edition, Walters Kluwer Company, Philadilphia, Vol. 255, 1690-1691.

[25] Al-Natour, S.H. (2009) Update in the Treatment of Cutaneous Leishmaniasis. Journal of Family and Community Medicine, 16, 41-47.

[26] Salmanpour, R., Handjani, F. and Noupisheh, M.K. (2001) Comparative Study of the Efficacy of Oral Ketoconazole with Intra-Lesional Meglumine Antimoniate (Glucantime) for the Treatment of Cutaneous Leishmaniasis. The Journal of Dermatological Treatment, 12, 159-162. https://doi.org/10.1080/09546630152607899

[27] Alsaleh Qasem, A., Dvorak, R. and Nanda, A. (1995) Ketoconazole in Treatment of Cutaneous Leishmaniasis in Kuwait. International Journal of Dermatology, 34, 495-497. https://doi.org/10.1111/j.1365-4362.1995.tb00622.x

[28] Alrajhi, A.A., Ibrahim, E.A., deVol, E.B., Khairat, M., Faris, R.M. and Maguire, J.H. (2002) Fluconazole for the Treatment of Cutaneous Leishmaniasis Caused by Leishmania Major. New England Journal of Medicine, 346, 891-895. https://doi.org/10.1056/NEJMoa011882

[29] Mameni, A.Z., Jalayer, T., Emam jomeh, M., Bashardost, N., Ghassemi, R.L. and Meghdadi, M. (1996) Treatment of Cutaneous Leishmaniasis with Itraconazole. Archives of Dermatology, 132, 784-786.

[30] Nassiri-Kashani, M., Firooz, A., Khamesipour, A., Mojtahed, F., Nilforoushzadeh, M. and Hejazi, H. (2005) A Randomized, Double-Blind, Placebo-Controlled Clini- 
cal Trial of Itraconazole in the Treatment of Cutaneous Leishmaniasis. Journal of the European Academy of Dermatology and Venereology, 19, 80-83. https://doi.org/10.1111/j.1468-3083.2004.01133.x

[31] Malek, M.J. and Ghosn, S.H. (2012) Infestations, Bites and Stings. In: Wolff, K., Goldsmith, L.A., Katz, S.I., Gilchrest, B.A., Paller, A.S. and Leffell, D.J., Eds., Fitzpatrick s Dermatology in General Medicine, 8th Edition, New York.

[32] Buller, P.G. (1988) Levamisole Therapy of Chronic L. Tropica. The Journal of Tropical Medicine and Hygiene, 81, 221-224.

[33] Dogra, J.A. (1991) Double Blind Study on the Efficacy of Oral Dapson in Cutaneous Leishmaniasis. Transmission of the Royal Society of Tropical Medicine and Hygiene, 85, 212-213.

[34] Dogra, J. (1992) Cutaneous Leishmaniasis in India: Evaluation of Oral Drugs (Dapson versus Itraconazole). European Journal of Dermatology, 2, 568-569.

[35] Sharquie, K.E., Najim, R.A., Al-Dori, W.S. and Al-Hayani, R.K. (2006) Oral Zinc Sulfate in the Treatment of Behçet Disease: A Double Blind Cross-Over Study. Journal of Dermatology, 33, 541-547. https://doi.org/10.1111/j.1346-8138.2006.00128.x

[36] Sharquie, K.E., Noaimi, A.A. and Khorshid, A. (2007) Topical Zinc Sulphate for Treatment of Viral Warts. Saudi Medical Journal, 28, 1418-1421.

[37] Sterling, J.C. and Kurtz, J.B. (2003) Viral Infections. In: Champion, R.H., Burton, J.L., Burn, D.A. and Breanthnach, S.M., Eds., Textbook of Dermatology, 6th Edition, Blackwell Scientific Publication, London, Vol. 26, 1029-1051.

[38] Sharquie, K.E., Noaimi, A.A., Al-Hashimy, S. and Al-Tereihi, I.G.F. (2013) Treatment of Tinea Corporis by Topical 10\% Zinc Sulfate Solution. The Iraqi Postgraduate Medical Journal, 12, No. 2.

[39] Sharquie, K.E., Al-Mashhadani, S.A. and Salman, H.A. (2008) Topical 10\% Zinc Sulphate Solution for the Treatment of Melasma. Dermatologic Surgery, 34, 1346-1349.

[40] Sharquie, K.E., Al-Noaimi, A.A. and Al-Shimary, F.A. (2005) New Intralesional Therapy for Basal Cell Carcinoma by $2 \%$ Zinc Sulphate Solution. Saudi Medical Journal, 26, 35961.

[41] Bafghi, A.F., Noorbala, M., Noorbala, M.T. and Aghabagheri, M. (2014) Antileishmanial Effect of Zinc Sulphate on the Viability of Leishmania Tropica and Leishmania Major Promastigoites. Jundishapur Journal of Microbiology, 7, e11192.

[42] Sazawal, S., Black, R.E., Jalla, S., Mazumdar, S., Sinha, A. and Bhan, M.K. (1998) Zinc Supplementation Reduces the Incidence of Acute Lower Respiratory Infections in Infants and Preschool Children: A Double-Blind, Controlled Trial. Pediatrics Journal, 102, 1-5. https://doi.org/10.1542/peds.102.1.1

[43] Sharquie, K.E., Al-Waiz, M.M. and Al-Noaimi, A.A. (2005) Condylomata Acuminate in Infants and Young Children. Topical Podophyllin Is an Effective Therapy. Saudi Medical Journal, 26.

[44] Eliston, D.M., Berger, T.G. and James, W.A.S. (2016) Parasitic Infestations, Stings, and Bites. In: Andrews' Diseases of the Skin, Clinical Dermatology, 12th Edition, Elsevier, Vol. 19, 401-405.

[45] Dart, R.C. (2004) Introduction to Plants. In: Medical Toxicology, 3rd Edition, Walters Kluwer Company, Philadilphia, Vol. 254, 1665-1671.

[46] Sharquie, K.E., Noaimi, A.A. and AL-Zoubaidi, M.S. (2014) Treatment of Actinic Keratosis by Topical 25\% Podophylline Sol. Journal of Iraqi Community of Medi- 
cine, 25.

[47] Oslen, D.G. and Dart, R.C. (2004) Skin and Mucous Membrane Agents. In: Medical Toxicology, 3rd Edition, Walters Kluwer Company, Philadilphia, Vol. 165, 1003-1004.

[48] Canel, C. (2000) Podophyllitoxin. Phytochemistry, 54, 115.

[49] Domingues, T. (1999) Immune Adherence-Mediated Opsonophagocytosis. The Mechanism of Leishmania Infection. The Rockefeller University Press, Vol. 189, 25-35.

Submit or recommend next manuscript to SCIRP and we will provide best service for you:

Accepting pre-submission inquiries through Email, Facebook, LinkedIn, Twitter, etc. A wide selection of journals (inclusive of 9 subjects, more than 200 journals)

Providing 24-hour high-quality service

User-friendly online submission system

Fair and swift peer-review system

Efficient typesetting and proofreading procedure

Display of the result of downloads and visits, as well as the number of cited articles

Maximum dissemination of your research work

Submit your manuscript at: http://papersubmission.scirp.org/

Or contact jcdsa@scirp.org 